\title{
Interfaces
}

INTERFACES Image Texte Language

$46 \mid 2021$

Jeux de Formats (2)

\section{6 details: the web is a place to give and share}

\section{Paula Varanda}

\section{(2) OpenEdition}

\section{Journals}

Electronic version

URL: https://journals.openedition.org/interfaces/3752

DOI: 10.4000/interfaces.3752

ISSN: 2647-6754

\section{Publisher:}

Université de Bourgogne, Université de Paris, College of the Holy Cross

\section{Electronic reference}

Paula Varanda, "96 details: the web is a place to give and share", Interfaces [Online], 46 | 2021, Online since 15 December 2021, connection on 16 June 2022. URL: http://journals.openedition.org/ interfaces/3752 ; DOI: https://doi.org/10.4000/interfaces.3752

This text was automatically generated on 16 June 2022.

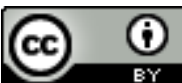

Les contenus de la revue Interfaces sont mis à disposition selon les termes de la Licence Creative Commons Attribution 4.0 International. 


\title{
96 details: the web is a place to give and share
}

\author{
Paula Varanda
}

1 The institutional concept of dance performance is grounded in the ephemeral and corporeal nature of dance and the logics of theatrical production. This tradition still shapes social understanding of the constitutive elements of dance artworks and frames spectator behavior and interpretation. However, an international community of choreographers have long experimented with format, exploring concepts and new media for the production and reproduction of their creations, venturing in new processes - choreographic, technological and interactive - that enabled successful migrations to other disciplinary fields and frameworks.

2 I have previously discussed 'migratory movements' to formats that enable dance to instantiate in cyberspace (Varanda, 'DPinC: Self and Social'; Varanda, 'Soi Moi'), and encourage innovative processes that transfer and transform the essence of dance. With appropriate operative concepts and in-depth analysis we can value the crossings of theatrical dance with other media and technologies (Varanda, 'New Media Dance'), and understand the significance of format changes for the intention, process and objects of dance artworks, as well as for their reception, at the level of access and audience participation, and academic or professional legitimization.

3 While the concern of documentation has driven dance research to preserve the legacy of an ephemeral art, new media studies have addressed the problem of disappearance in terms of technological obsolescence (as in Dekker; and Grau). The examination of a web-based dance in this paper aims to contribute to the validation of its aesthetic quality; revealing the operations of transfer and transformation; and inscribing the work in the history of dance performance and new media art with academic writing.

4 Created by Compagnie Mulleras (France 2006-2009), 96 details is an open work with worldwide outreach that invites users/spectators to play choreography with one dancer. This approach is innovative, but marginal in the institutional canon and circuit; why did the artists invest in this format? How did they explore technology and internet 
art principles? What traces remain of contemporary dance? Is this format legitimate for dance? What have they gained?

The choreographers initiated a path of pioneer research twenty years ago which I have been following for a decade. In the context of the last two years, when people have been obliged to stay home in order to keep safe from a viral pandemic, 96 details becomes poignantly pertinent, for the artists removed from their live performance environments who were forced to rethink their medium, and for the audience to access a global venue for dance.

\section{The web as theatre and venue}

6 Didier and Magali Mulleras founded their company in 1990 in Béziers; they wanted to establish a professional regular offer of dance classes and performances in a small town in the south of France, as well as promoting an international contemporary dance company with distinctive choreographic process and aesthetics. In 1998 the company started integrating multimedia technology into its creative process, which it maintained until 2010, with the web-works Mini@tures (1998-2001), followed by Invisible (2002-2005), and lastly 96 details. ${ }^{1}$ In 2010 I interviewed Didier Mulleras about the company's work; ${ }^{2}$ at the time he referred to their interest in following "a parallel composition (écriture) of the same work, experimenting how dance and music, body and sound, express and combine in different media". Thus, the choreographers were generating two models of presentation from the same creative enquiry as web work and stage performance. ${ }^{3}$ Such procedure, Didier explained, allowed them to maintain a connection between the live and the digital body.

7 In Mini@tures, the choreographers used the web as a "space for creation and experimentation of an idea of mini stage (miniplateaux)", with a collection of 100 short films organized in ten series of several episodes. They received rewarding feedback: "Three months later we were receiving emails from the audience, and there were programmers wanting us to travel, asking for a stage production" (Didier Mulleras, in interview).

8 The press reported on the distinctive approach of this work, that deconstructs the idea that the material body is overtaken in cyberspace (Boisseau in Télérama), ${ }_{4}^{4}$ saying the company "has perfectly adapted dance to the web" (Lechner in Libération), ${ }^{5}$ and mitigated the isolation of a small touristic village from the international professional dance circuit (interview in L'Art-Vues). ${ }^{6}$ The Mulleras were crossing the site-specific boundaries associated with different disciplines, transforming working habits and making dance reproducible and visible, through screen interfaces, of a high quality in technical terms (Corin 191). ${ }^{7}$

9 Publishing the projects on a web format was important to keep visibility and audience engagement after the live performances. Didier recalled in interview that he saw the internet as "the smallest but also the biggest theatre room of the world", that enabled independent distribution away from institutional circuits of theatres and commissioners.

1096 details configures the characteristics of internet art (Greene), and has the layout of multimedia online works, where the electronic interface of a web-page becomes a studio with opportunities for display that extend outreach (Popper). Dance studies 
have classified this practice as hyperchoreography (Fildes and McPherson) or hyperdance (Bench, 'Hyperdance'). Bench and Fildes in these texts, as well as Popat and Dixon in their own work, have significantly contributed to map and contextualize several artists and artworks in this field that comprises different approaches to digital technology and interactivity. These authors refer to compositions by Amanda Steggell, such as M@ggie's Love Bytes (1995) and Richard Lord - Progressive 2 (1996) and Brownian Motion (1997) - as early examples, followed by others such as Clauss and Silhol Sonnambulles (2003) - , Fildes and McPherson - The Truth : The Truth (2004) - , Richard Siegal's If/Then Open Source (2006), and Bibap Project by Carolein Hermans (2008).

11 All the above choreographers, including Compagnie Mulleras, have used, in the terms of Auslander, "cyberspace as a performance art venue" (123), and in this format, as Rubidge has defined, the relationship between artwork and audience brings "new states of affairs into being" ('Performing Installations' 365). I interviewed Didier Mulleras in order to understand the motivation and creative process from the artists' perspective and undertook structured observation of the way the dance works internally (Adshead-Lansdale). A descriptive task - on content and interface - is accompanied by literature review that contextualizes the form and experience of this dance performance in cyberspace.

\section{Themes and structure}

The concept behind 96 details is a 'living picture' where the body is a designer of lines and patterns, leaving a trace of presence, of being human, in the digital environment. On the website, the work is described as "a suite of artistic modules, able to function close or far from each one. A polymorphic work, which declines its units almost infinitely; a puzzle to be discovered by a fragment or by fusion of each element". ${ }^{8}$ This distinctive characteristic of the project signals the basis of its originality and complexity: it is made of multiple parts, not necessarily all engaged in one single contact with the piece - suggesting the interest of a number of returns. On a choreological ${ }^{9}$ perspective the work pursues "a medium idea" (Preston-Dunlop and Sanchez-Colberg 18), exploring two lines of enquiry: dance making and its delivery as an interactive online piece.

In order to examine systematically such complexity, I had to map and catalogue the existing sections that compose the whole (Figure 1) and I listed their characteristics in terms of costume and performer, choreographic phrase and sound, space and visual effects, camera Point of View, and interactive features. With this method I identified twelve interactive sections, and I selected eight that were representative of the variations in terms of performer, movement, visual and aural elements, and interactive possibilities (details $2,4,5,6,13,16,17,18$ ). As we enter the 96 details webpage, a spinning cube unfolds into six faces, each divided in $8 \times 8$ small squares. From this 'foyer' we can access each micro-dance. ${ }^{10}$ The choice to name the unit "detail" was made to reflect on the way things that appear to be insignificant may turn into rather important triggers for exponential action, which here is manifested choreographically. 
Figure 1. Map of sections in 96 details, composition with screenshots.

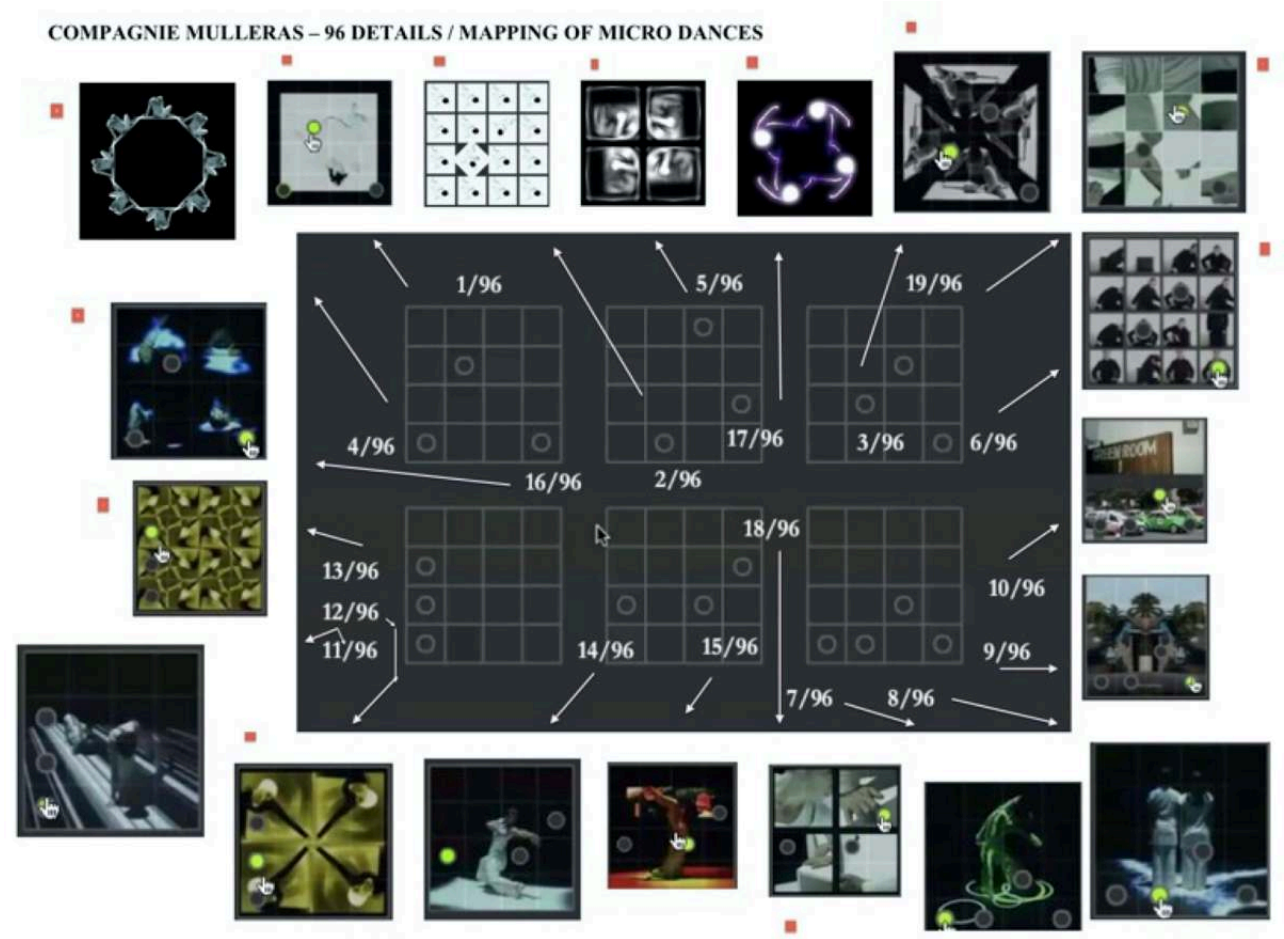

(c) Paula Varanda.

\section{Space and place}

The cube is a formal feature that led the team's research and defines the performance space, framing the dancer in a square, but maintaining a tri-dimensional structure where the body could move, and the camera shifts plane, vertically and horizontally. 96 details' visual environment replicates the neutral theatrical stage that is not unusual in contemporary dance performance. This was nonetheless a technical solution to the requisites of the small screen and the small resolution films; as Didier points out: "there was not much area to develop an idea of space"; the result is a techno-aesthetic quality that Bench conceptualizes as No-place: "an abstracted space, a blank or evacuated scene. It is, in this sense, nothing. [...] abstracted from built or natural environments that would situate their movement, bodies wander through space with an illusory freedom, unrestricted by physical or ideological barriers (Bench, 'Media and the No-Place of Dance' 37).

In videodance, as Dodds remarked, artists "explore certain camera perspectives to create spatial possibilities that could not be achieved on stage" (71). In 96 details the same sequence was filmed simultaneously from three fixed angles providing different perspectives (Figure 2): from the top shot, the body is confined by the square (detail 2); from the front the performer is seen to move against a dark background (detail 4); and from a frontal but tilt down shot the space combines a white floor surface with the black void (detail 3 and 16). While the first two camera positions emphasize flatness, the tilt angle gives a sense of depth. 

choreographic triggers, all contribute to expanding the original studio space into the living picture. The display intentionally affiliated the piece with visual arts traditions, but at the same time, for Didier Mulleras, it draws the attention to "the body as an agent and the body as art".

Figure 2. 96 details, three camera angles, screenshots of details 1, 3 and 4.
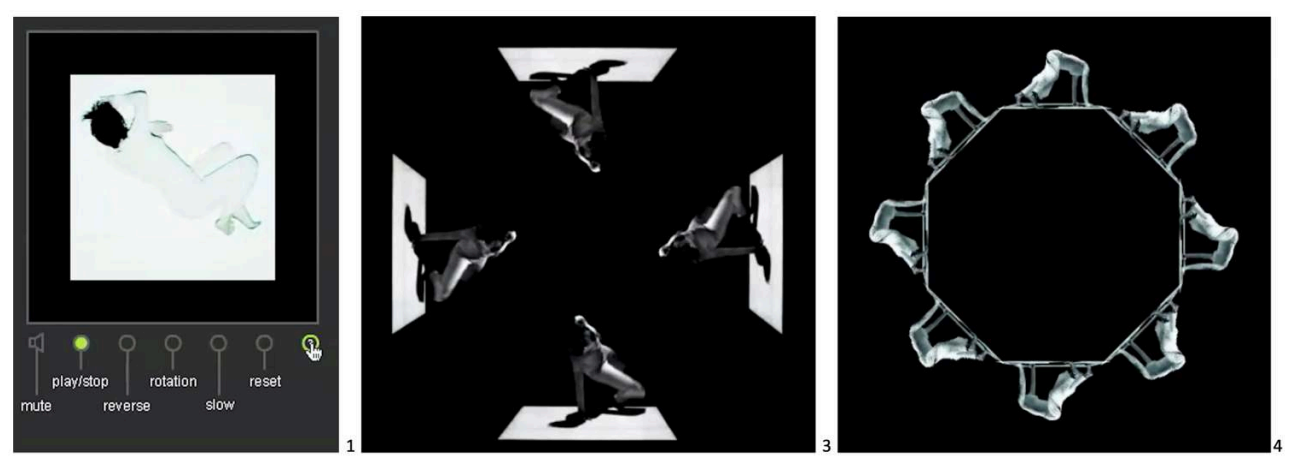

(c) Paula Varanda.

\section{Body and performer}

17 The performer's action is captured into a 2-dimensional photographic representation with the use of video technology (Figure 3). A female performer integrates the twelve sections prepared for creative interactivity, and she wears a neutral combination of shirt and trousers, varying between full white (in details 2, 4, 13, 16 and 18) and full grey (detail 5) or full black (detail 6). Although 96 details is a solo performance, the solo is often multiplied with film duplicates running simultaneously, giving the impression of a group performance.

Figure 3. 96 details, costumes and visual treatment of the performer, screenshots of details 2, 6, 13, and 17.
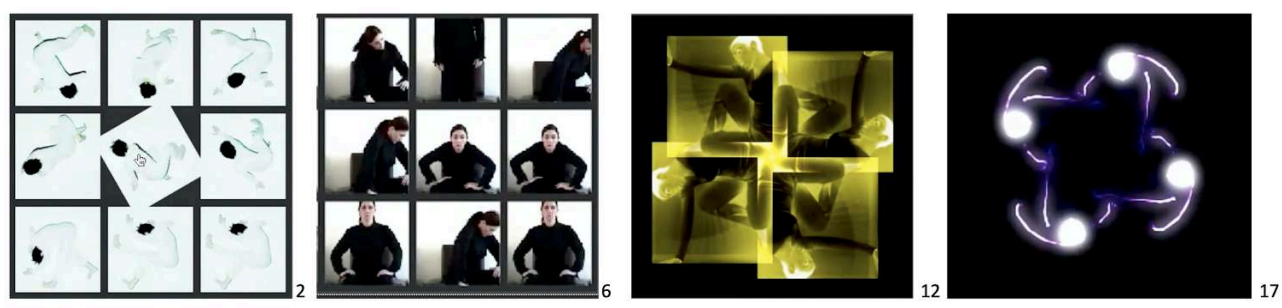

(C) Paula Varanda.

18 The simplicity of costumes emphasizes the body as a moving agent and corresponds to technical demands and the purpose of combining fragments within a same section and playing with drawing lines, shapes and patterns. The character of the performer relies mostly on the movement and its relation to the environment; her face is rarely perceptible in most of the details, and in some of them $(5,13$ and 17$)$, filter effects such as blur, negative and solarizing change the body's visual representation and increase abstraction, dissolving the human body, and particularly the identity of the performer, into abstract drawings and patterns. 

short phrases that were programmed to loop. The operation of multiplication, used in 10 of the details, was discovered in the capturing process, as Didier recalls: "we realized that the idea of pattern could happen, and so we re-worked the choreography". The movement phrases (between 10 seconds and 1'30"), are fragmented and multiplied in different ways, and achieve effects such as symmetric mosaics (details $2,3,4,5,12,13$ and 17) or flowing canons ${ }^{11}$ (details 6,16 and 18), which vary according to the times each film is reproduced: 4, 8, 9 and 16 .

The movement style corresponds to references to Western contemporary dance prominent in the 1980s and 1990s and is summed up in five short movement phrases (Figure 4). The choreography combines Laban's kinesphere explorations, floor and contact work, and a mix of author-devised vocabularies. In phrase 1 (details 1,2, 3, 4, and 16), the woman rolls on her knees, opens her arms, closes her legs, turns the torso, sits or lies down, looks towards the viewer or around herself in a smooth but rhythmic pace. The dancer finds choreographic solutions for the confined situation. In phrase 2 (details 5, 12 and 13) the torso and arms extend further and push against the limits of the space, stressing the enclosure. Phrase 3 (detail 6) is gestural and the performer, sitting on a chair, looks frontward, moves the head upwards and the torso sideways with impulses of the knees. Phrase 4 is more dynamic and expansive (detail 17), with steps around the space, arm swings, and spirals around a vertical axis. Finally, in phrase 5 (details 18 and 19), two women move around a white box, with four close-up shots, that show faces or body parts. 


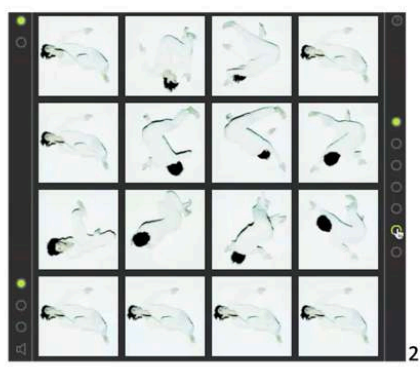

Phrase 1 - details 1, 2, 3, 4, 16

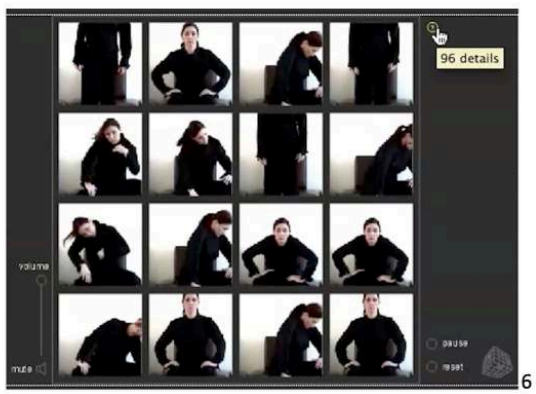

Phrase 3 - detail 6

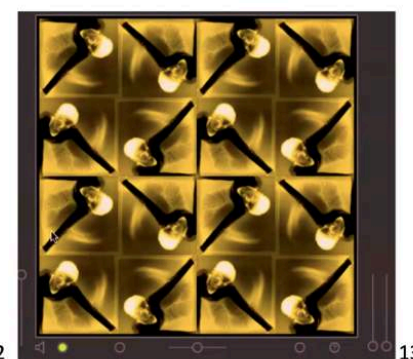

Phrase 2 - details 5, 12, 13

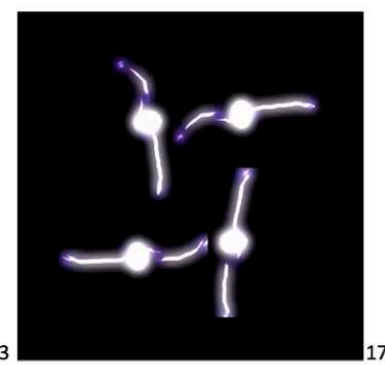

Phrase 4 - detail 17

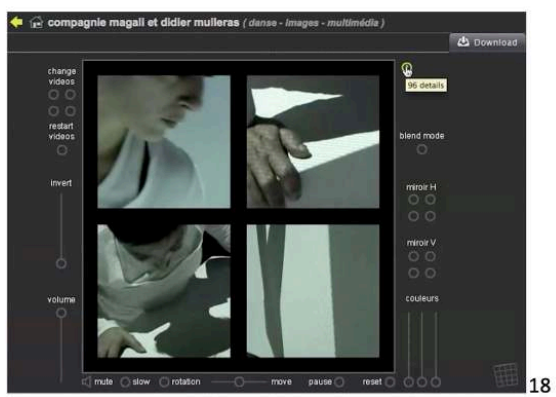

Phrase 5 - details 18,19

\section{(c) Paula Varanda.}

In 96 details various layers of choreography accumulate: the 'raw' movement phrase, the framing space, the camera angle and shot size, and editing choices like cut and speed. ${ }^{12}$ These variations enhance the perception of choreography, change the space of the performance and create different micro-dances. The sound contributes to the sensorial experience of the piece with 8 short loop compositions of electronic timbres and rhythms, vocal or instrumental, of higher and lower pitch, providing a continuous pulse that supports the movement routines, emphasizing their rhythmic and swaying quality.

Auslander considered that for cyberspace to become a venue of medium-specific artworks "artists will have to find ways of translating their artistic concerns into performances that can be undertaken by virtual performers" (126); on the basis of technical constraints the choreographers of Compagnie Mulleras determined the aesthetics of the project: small size, short takes, small movements, light atmosphere. 96 details demanded meticulous research about the possibilities to use the webpage as a stage:

We devised choreographic phrases so that they could be seen from above, and we made discoveries in terms of vocabulary, because there were some movements that did not work and in other cases, only some kinds of movements would work, depending on the planes used. (Didier Mulleras, in interview)

Despite the apparent simplicity, explicit fragmentation and new media 'nature' of 96 details, the expert-intuitive knowledge of the choreographers is essential to make the work effective and engage the spectator in a dance experience via an unlikely medium in an improbable site. In their migratory movement, the Mulleras kept the organizing principle of choreographic concepts, which Rubidge pointed out as a characteristic that 
differentiates digital dance from other digital artworks (Rubidge, 'Defining Digital Dance'). Choreography is a defining element for new media dance (Varanda, 'New Media Dance') and for the company it was an organizing principle from the start; in Mini@tures, Didier remarked, they “wanted to work more on the choreographic than on the cinematographic" (in interview).

\section{Interface and interactivity}

The interface is a desktop or portable computer, with screen displays between 13 to 20 inches, ${ }^{13}$ and commercial creative software of the early 2000s. Located in the worldwide communication space opened by the interconnection of computers, that Levy defined as cyberspace (107), the work was accessible from any device with internet connection, a web browser, and flash player software.

The interactive model is based on click on/off, using a mouse pad to navigate the web page, where text information and icons, guide the entrance into the work and the interactivity with each detail (Figure 5). Based on windows, menus and mouse activation, this was a dominant interface for the model of human-computer interaction (HCI) until the early 2000s, where control options are explicit through graphic information to facilitate interactivity (Dourish 12-14). 96 details follows a closed HCI model, which was characteristic in the 1990s web-based dances (Popat 48-49): the user engages with the work without the author's real time co-presence; the dialogue between author and audience is asynchronous and mediated by the electronic media that displays the artwork. Dixon classifies this as "navigation interactivity", describing it as a basic form of relating with content and producing a customized effect (566). ${ }^{14}$

Figure 5. 96 details image, sound and film controls, screenshot of detail 16.

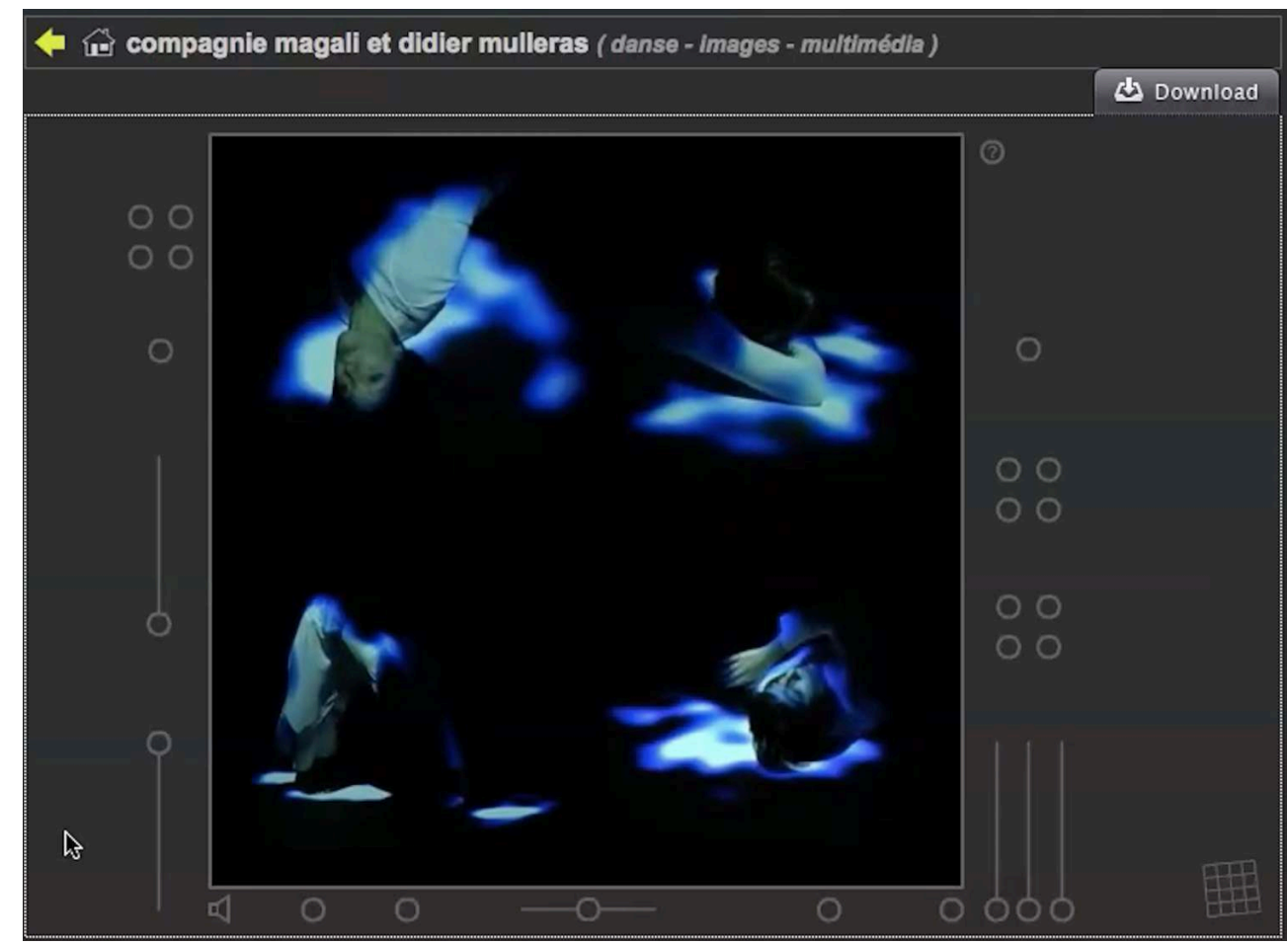

(C) Paula Varanda. 
itor chooses which detail to watch and participates in its creative development by clicking images and buttons and changing various options and parameters: we can flip, rotate or move the films, pause and restart the movement sequence or sound, change the speed or colour of the image, choose colours and visual effects. The feedback of the control buttons are easy to identify and the work-flow is never interrupted (Souza). It is a case where hypermediacy emphasizes the performative process and operates successfully, making the visitor aware of the media in a playful way (Bolter and Grusin); such awareness contributes to increasing the sense of immersion (Bolter and Gromala) and influences the aesthetics of experience; with appropriate design, 96 Details compensates the complexity and possibilities of computer technology (Norman).

\section{Partaking and authorship}

By clicking buttons or clips the user/spectator creates patterns and abstract drawings from the multiplication of units of human movement, turning the potential into actual choreography. The authors wished to "increase the options for the audience to be able to manipulate this material and make something really unique of them" (Didier in interview). This idea engages 96 Details with the debate about authorship in contemporary and participatory art.

Performance and Dance Studies have discussed authorship in terms of the role of performer (and other contributors), to the signature of the choreographer that identifies the work (McFee), ${ }^{15}$ or in the role of the spectator as a creative reader of the dance 'text', who participates in transitory clarification of ambiguous utterances (Adshead-Lansdale). For Birringer, similarly to a theatre event, the interactive artwork "is designed in explicit anticipation of its user: it is always becoming and never completed" (180). However, the participated and ephemeral transactions allowed in 96 Details, bring a new stance to the triadic relationship between choreographerperformer-audience that Preston-Dunlop and Sanchez-Colberg have identified as a principle of the dance medium.

31 The principles of new media described by Manovich (27-48) are operative in this artwork since the performers, sounds and spaces need digitization to be numerically represented; the source data is organized in modular parts, that duplicate the original in different ways (shorter, faster or smaller parts, for example); automatic responses are programmed; and the content, unlike a fixed film, may be variably assembled. But Manovich rejects the notion of co-authorship in order to speak of the result of interactive artworks per se. Popper, on the other hand, considers the user as a contributing author when autonomous agency influences the aesthetics of the work. Rubidge makes a distinction between the artist who creates and produces the work and the creative visitor, who is the co-author of the work-event (Rubidge, 'Identity in Flux: A Practice-Based Interrogation of the Ontology of the Open Dance Work'); her specification suits what happens in 96 Details, and suggests the interest in evaluating and theorizing a transaction that shifts, in Birringer's terms, from an aesthetic of contemplation to an aesthetic of experience (182). 


\section{Affect and play} Although this interaction is mediated by the screen and the mouse control, in her view this experience affiliates with Contact Improvisation, because while "tracking moment-to-moment changes, the responsive body receives, interprets, and responds to sensory information accordingly" (5). Interacting with the body in motion is central to kinesthetic empathy (Reason and Reynolds), ${ }^{16}$ which contributes to the affective engagement of spectators. In 96 details, the body of the performer and the soft pace of her action create a sense of intimacy, which enriches the private encounter that occurs between the audience and the artwork. Thus the work can be evaluated in terms of embodied experience, rather than intelligibility; Hansen observed that sensorimotor engagement is a deliberate intention of new media artists, that can be "understood as efforts to specify what remains distinctly "human" in this age of digital convergence" (12). In the interactive new media dance work, Bench remarks that "body and image are surfaces in contact, and they do reciprocally inflect each other" ('Of Skins and Screens' (12).

Playing, Dixon underlines, is another important feature for audience engagement and "[i]nteractive works encourage a playful, childlike fascination for the pleasure of cause and effect" (598); the sense that a simple action-command can transform "something outside of oneself" (idem) has the powerful effect of establishing intimate connections between the individual and the outer world. Fildes has remarked that his hyperchoreographies ${ }^{17}$ take advantage of the game-play aspect of interactivity, encouraging the viewer to engage choreographically with the content and make customized versions (Fildes). 96 details instigates creative play with rhythms, shapes, sounds, movement and colours; for the spectator who is sensitive to such types of artistic interplay, mediated by machines, the experience can be quite compelling.

Manovich considers looping as a form of organizing narrative, that emerges in compositions with new media (2001). For Bench, in Hyperdance, "repetition, in the guise of the replay loop, has flourished as a practical means of enabling continuous motion, while at the same time maintaining manageable file sizes and processing speeds" ('Computational Choreographies' 195). In 96 details loops of aural and visual materials ensure continuity and facilitate immersion in the kaleidoscopic constructions of multiplied fragments. The transaction is characterized by an affective and playful engagement with choreographic improvisational events; these events resonate and excite our own body because, as Shusterman reinforces "all affect is somatically grounded" (153). In my own experience of 96 details, the quick feedback sustained my interest and enhanced the consciousness of my role. I played with the work many times and during these transactions I acknowledged the worth of the work by appreciating its intrinsic 
techno-aesthetic quality and complexity. I have recorded several of these experiences and a compilation of this material is accessible online in a short video ${ }^{18}$. Partaking of this dance performance in cyberspace, from my domestic environment, was essential to embody a poetic reading of the work. Including that narrative in the analysis is a methodological option: the researcher steps into the actual experience, without which, in Kwastek's terms (64-65) the account and assessment of the artwork are incomplete. The following events are an informal narrative of those experiences.

\section{Event 1: Mandala Dance}

I launch detail 4 and an octagonal shape resulting from two juxtaposed squares appears against a black void; inside the bordering lines a white mosaic form is moving in a pulsing way, filling in or emptying the octagon's centre (Figure 6). I contemplate this for a while, and then select and shift the 'move' control to the right, which opens the octagon outwards; the border lines are a floor surface and the internal moving form is the performer dancing. I realize that the mosaic is a result of eight replicas of the same film (phrase 4). Now I can appreciate the choreography in full, with the whole body moving, and enjoy the effect of multiplication: the sense of one person becoming a group in unison, and the mosaic of a concrete human body that fills the negative space of the scene. ${ }^{19}$

Figure 6. 96 details, user sequence with detail 4, screenshots of recorded interactive event.
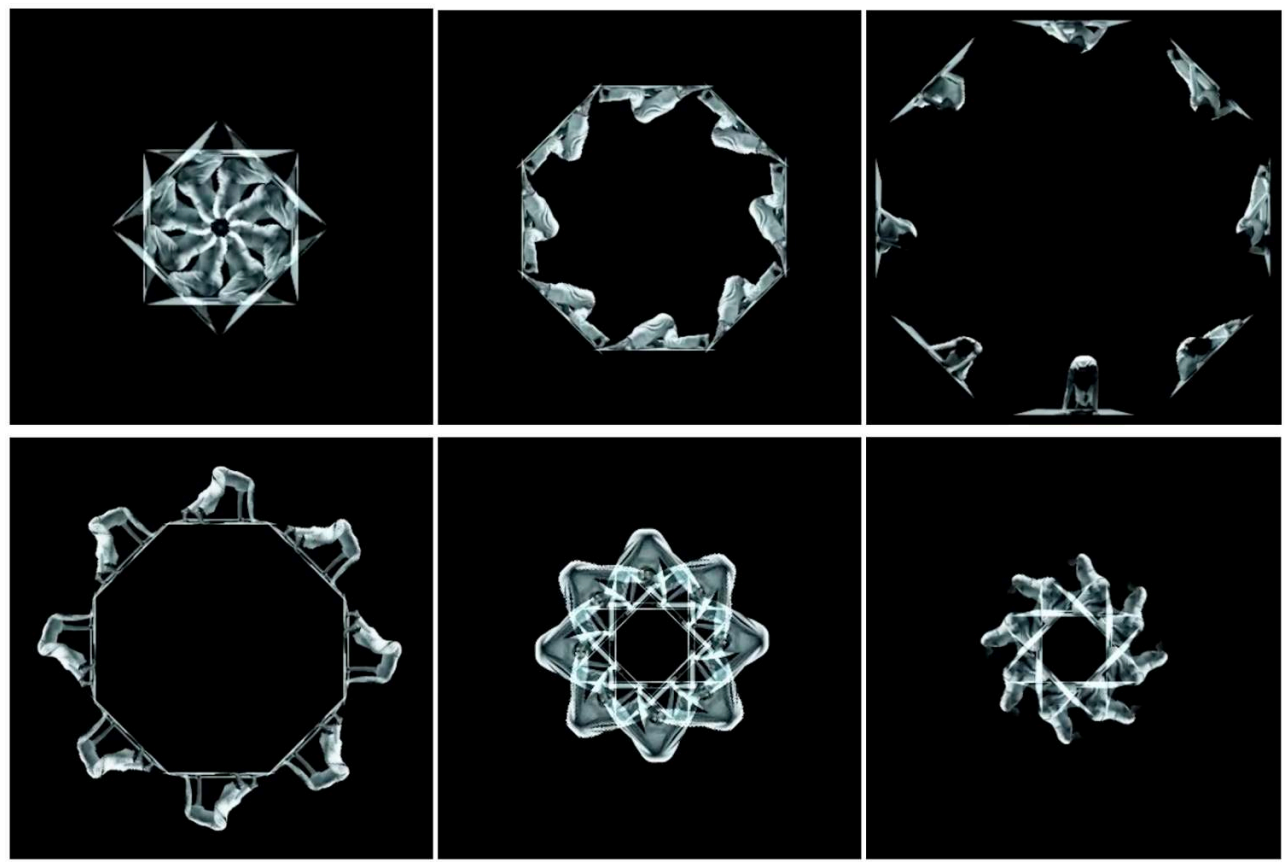

(c) Paula Varanda.

38 The contrast between dancer and black void catches my interest; it enhances body contour and movement details, and triggers a sense of beauty and solitude. After observing this detail for a while, I press the 'décalage' control and each dancer's replica (I cannot tell which is the original), initiates the phrase from a different point and a round-canon effect takes shape on stage. Because the multiplied dancer maintains the 
octagonal frame, a new choreographic layer emerges from the progression of the basic set in a circular line counterclockwise; I enjoy this movement and I stay still, appreciating it for a while.

I then proceed to the 'move' control on the left, which draws the eight parts together towards the centre. I play with this control: moving outwards and inwards, slower or faster; I experience the effects in drawing the negative space or in the relationship between the body movement and the mosaic angles.

If I drag to the left the eight bodies are separated again, but now the floor borderline is inwards, so the performers seem to be all attached to the same floor. If I continue dragging the cursor in that direction, I increase the juxtaposition of the multiplied dancers, that stimulates the perception of an abstract image. I am entranced, guided by the pulsing of a continuous bass line sound. I find it magical. Inspired by the sense of infinity and the round mosaic moving shape, I named this event Mandala dance.

\section{Event 2: Touching and Sliding}

In detail 18, I find the 'stage' divided in four squares, each displaying a different film, which is a fragment of a longer dance sequence (Figure 7). Camera movements with close-up shots accompany the dancer, who is moving over a white wooden box. In the top left square the woman encircles the box, which supports the hands or the back from left to right (film a); in the top right square, her hand is pressing towards the left and a foot glides towards the right (film b); in the bottom left she touches the surface, slides her hand through and leans her torso and head (film c); in the bottom right square, the box is turned over towards the left with the hands (film d). The aural atmosphere is a syncopated rhythm on a three/four bar section, on top of which a bell sounds lengthily (a 6-second loop).

Figure 7. 96 details, user sequence with detail 18, screenshots of recorded interactive event.
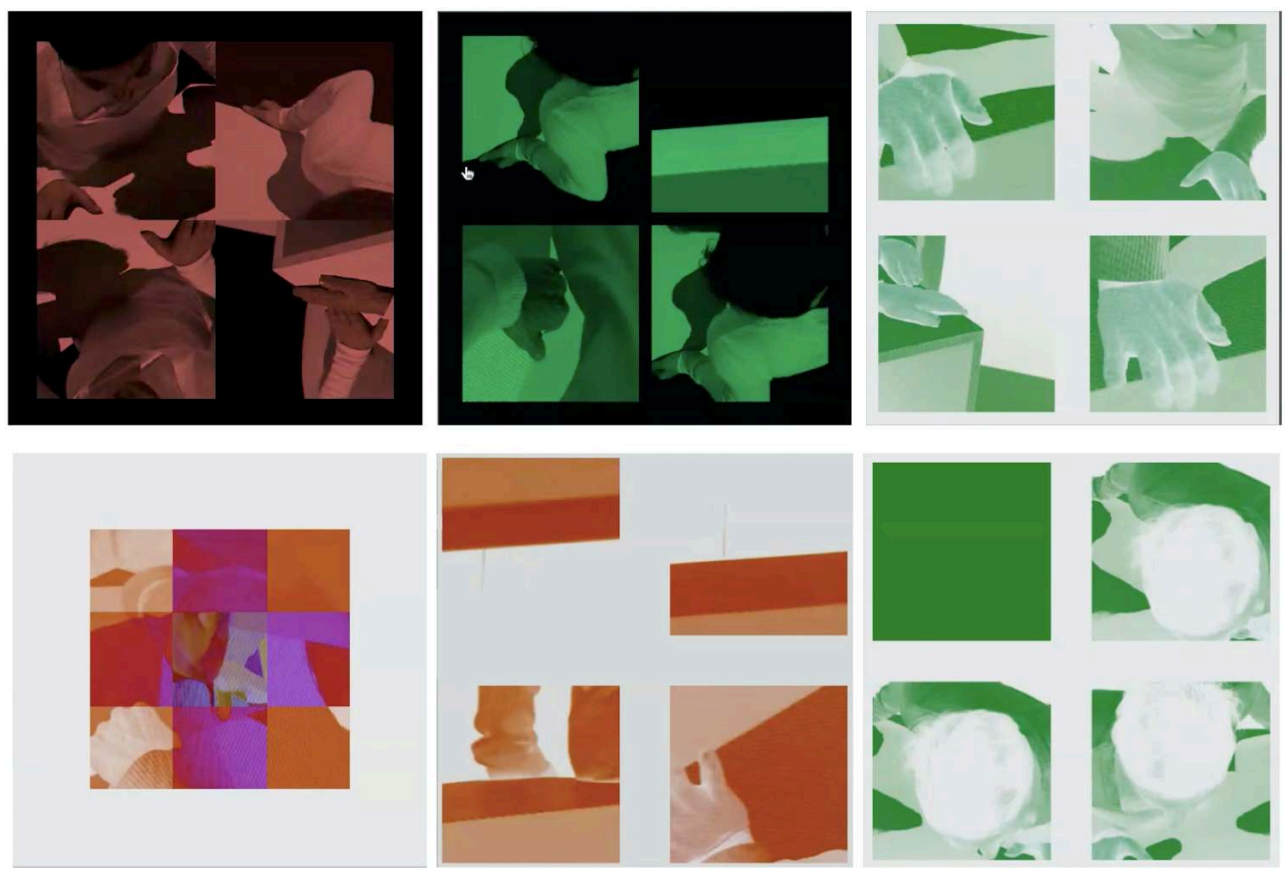

(c) Paula Varanda.

Interfaces, 46 | 2021 

such experience is grounded in choreographic utterances and nurtures an affective relationship with the other (embodied by the performer), that softens the screen flat surface and the synthetic material hardware (Figure 8). They perform, in practice, Popper's argument that artists who make virtual art pursue a techno-aesthetic commitment, which has the effect of humanizing technologies (5), invading the 
functional with the subjective or, in Massumi's terms, the abstract rational with the concrete virtual. They did so engaging with the web in a way that Popper describes as: "a space for experiencing art - a space with its aesthetic rules, and a privileged place for converting information into imagination" (371), and their approach resembles the low-fi aesthetics that Greene recognizes in projects that want to "demystify, domesticate and familiarize technologies" (200).

Figure 8. 96 details, user compositions, screenshots of details 13 and 5.
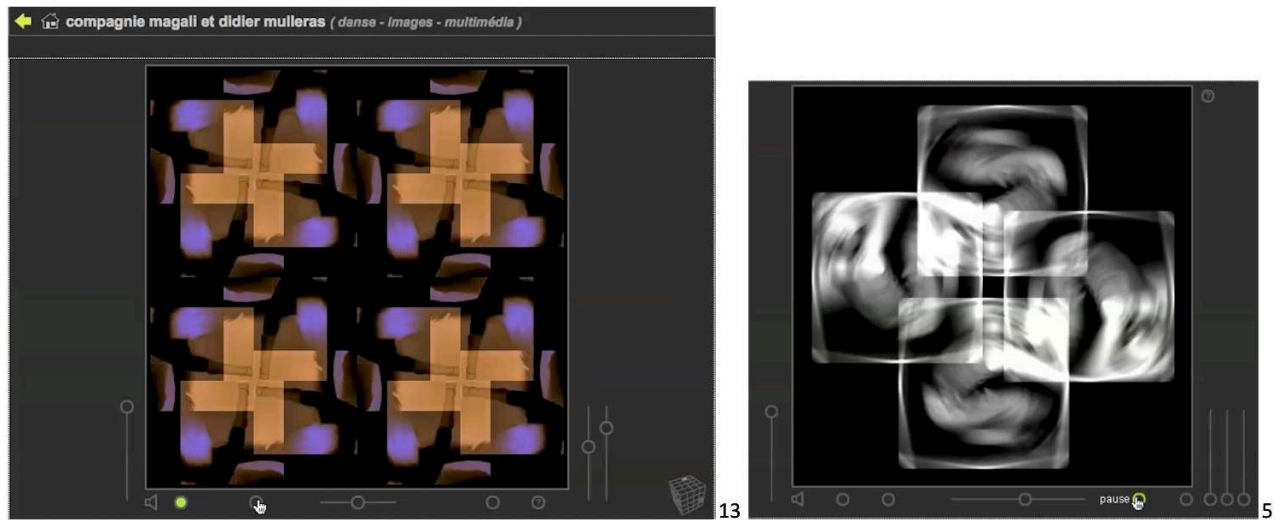

(c) Paula Varanda.

This proposal of a free encounter, that can take place across the globe at any time, undermines the dominant status of theatrical dance performances and Didier Mulleras admits that it is very difficult to get funding for net $\operatorname{art}^{20}$ and on the side of the public, the web is associated with the principle of free access ${ }^{21}$. The choreographers invested in a laborious project such as 96 details and then offered it to the world, because their creative endeavor is entrenched with a philosophical attitude:

On stage we are a company with everything in place in terms of economy; our shows are sold and we are a professional company as such, from very early, in the 1980s. But with the internet it is different; I like to have it as a free thing. In the web our art is free for everybody. This also gave me a different space to create, I could be much more free of all the value that was put in the art as a commodity. I could create an alternative to that economic logic (Didier in interview, 2010).

The Mulleras have made an original and significant contribution to the field of practice and theory that converges conventions from both the live and the digital territories of expression. In interview, Didier Mulleras expressed satisfaction with the outcome and outreach achieved but he regrets that screen projects in dance are much less valued than stage productions. The institutions started referring to them as multimedia artists and disregarding their expert position as choreographers. Didier finds that "the whole system is suspicious about dance artists that move to another medium like the net"; and internet art, as Greene remarks, is considered a "marginal practice, which often has an antagonist position to that of the institutional circuit of production, exhibition and trade" (11). The World Wide Web hosts numerous activities and, as Wilson points out, "information arts" are seen as derivative from mass media and domestic production (26-27). The marginal position of the web dances of Compagnie Mulleras is not justified by the work itself, but by the lack of an institutional framework with the skills to legitimate its worth, singularity and quality. 
51 Within the dance community that has to work hard to make their work economically valued and professionals depending on institutional legitimization and financial support to survive from their activity, the position of Didier Mulleras is unusual: "the web does not bring money, and that is why choreographers don't do that so much", furthermore in addition to the multidisciplinary skills required, he is aware that "to get to a result that is a work of art that is free is not very interesting for most people". Didier is not afraid of being copied and is not concerned with copyright because, he says, "we know, from the beginning, that we are going to give"; in a society where all is sold and has economic value, they maintain a notion of value, investment and return that is not just measured financially: "things come back in a different way, people's comments, press coverage, people buying our pieces on stage, that is also very important".

96 details is an outstanding piece due to intrinsic qualities and extrinsic characteristics. Popper remarks that artists carry with their own techno-aesthetic signature ideals related to extra-artistic issues that are of major significance to their culture; they embed these technologies with values of freedom and community, namely by exploring the notion of public art on the Internet, developing open source software and creating platforms for professional networking and audience participation in collective authorship proposals (Popper 314). This is certainly the case of Compagnie Mulleras, as I have aimed to demonstrate by sustaining the consistency of 96 details as an inspiring example, for audiences that had the pleasure of this experience and other artists that may want to explore dance within new media formats of dance.

\section{BIBLIOGRAPHY}

\section{Works cited}

ADSHEAD-LANSDALE, Janet, editor. Decentring Dancing Texts: The Challenge of Interpreting Dances. Palgrave Macmillan, 2008.

AUSLANDER, Philip. ‘Cyberspace as a Performance Art Venue'. Performance Research, vol. 6, no. 2, 2001, pp. 123-27.

BENCH, Harmony. 'Computational Choreographies: Performance in Dance Online.' International Journal of Performance Arts \& Digital Media, vol. 5, no. 2/3, Dec. 2009, pp. 155-69. https://doi.org/ 10.1386/padm.5.2-3.155/1. [accessed 12-10-2020]

BENCH, Harmony . 'Hyperdance: Dance Onscreen, Dance Online. Or, What Difference Does the Medium Make?' Screendance: The State of the Art Proceedings, ADF - American Dance Festival, 2006, www.dvpg.net/screendance2006.pdf. [accessed 12-10-2020]

BENCH, Harmony. 'Media and the No-Place of Dance'. Forum Modernes Theater, vol. 23, no. 1, 2008, pp. 37-47. 
BENCH, Harmony. 'Of Skins and Screens: Hyperdance, Haptic Cinema, and Contact Improvisation'. Extensions: The Online Journal of Embodiment \& Technology, vol. 3, 2007 http:// www.performancestudies.ucla.edu/extensionsjournal/bench.htm. [accessed 24-05-2010] BIRRINGER, Johannes H. Performance, Technology, \& Science. PAJ Publications, 2008.

BOLTER, J. David, and Diane GROMALA. Windows and Mirrors: Interaction Design, Digital Art, and the Myth of Transparency. MIT, 2003.

BOLTER, J. David, and Richard GRUSIN. Remediation: Understanding New Media. MIT Press, 1999. BRANNIGAN, Erin. 'Micro-Choreographies: The Close-up in Dancefilm.' International Journal of Performance Arts \& Digital Media, vol. 5, no. 2/3, 2009, pp. 121-39.

CORIN, Florence, editor. Danse et nouvelles technologies. Contredanse, 1999.

DEKKER, Annet. Collecting and Conserving Net Art: Moving beyond Conventional Methods. 1st ed., Routledge, 2018, https://doi.org/10.4324/9781351208635. [accessed 2-10-2019]

DIXON, Steve. Digital Performance: A History of New Media in Theater, Dance, Performance Art, and Installation. MIT, 2007.

DODDS, Sherril. Dance on Screen: Genres and Media from Hollywood to Experimental Art. Palgrave, 2001.

DOURISH, Paul. Where the Action Is: The Foundations of Embodied Interaction. MIT Press, 2001.

FILDES, Simon. From Hyperchoreography to Kinaesthediting. hyperchoreography.org, May 2008, http://www.hyperchoreography.org/writing27.html. [accessed 6-12-2020]

FILDES, Simon, and Katrina McPHERSON. On Hyperchoreography. hyperchoreography.org, 2001, http://www.hyperchoreography.org/writing1.html. [accessed 6-12-2020]

GRAU, Oliver. 'The Complex and Multifarious Expressions of Digital Art and Its Impact on Archives and Humanities'. A Companion to Digital Art, John Wiley \& Sons, Ltd, 2016, pp. 21-45. Wiley Online Library, https://doi.org/10.1002/9781118475249.ch1. [accessed 15-9-2019]

GREENE, Rachel. Internet Art. Thames \& Hudson, 2004.

HANSEN, Mark B. N. New Philosophy for New Media. MIT Press, 2004.

KOZEL, Susan. Closer: Performance, Technologies, Phenomenology. MIT Press, 2007.

KWASTEK, Katja. Aesthetics of Interaction in Digital Art. The MIT Press, 2013.

LEVY, Pierre. Cyberculture. University of Minnesota Press, 2001.

MANOVICH, Lev. The Language of New Media. MIT Press, 2001.

MASSUMI, Brian. Parables for the Virtual: Movement, Affect, Sensation. Duke University Press, 2002.

McFEE, Graham. The Philosophical Aesthetics of Dance: Identity, Performance and Understanding. Dance books, 2011.

McPHERSON, Katrina. Making Video Dance: A Step by Step Guide to Creating Dance for the Screen. Routledge, 2006.

MELROSE, Susan. 'Bodies Without Bodies'. Performance and Technology: Practices of Virtual Embodiment and Interactivity, edited by Susan Broadhurst and Josephine Machon, Palgrave Macmillan, 2006, pp. 1-17.

NORMAN, Donald A. The Design of Everyday Things. [New] ed, BasicBooks, 2002.

POPAT, Sita. Invisible Connections: Dance, Choreography and Internet Communities. Routledge, 2006. 
POPPER, Frank. From Technological to Virtual Art. MIT Press, 2007.

PRESTON-DUNLOP, Valerie, and Ana SANCHEZ-COLBERG. Dance and the Performative: A Choreological Perspective: Laban and Beyond. Verve, 2002.

REASON, Matthew, and Dee REYNOLDS. 'Kinesthesia, Empathy, and Related Pleasures: An Inquiry into Audience Experiences of Watching Dance'. Dance Research Journal, vol. 42, no. 2, Winter 2010, pp. $49-75$.

ROSENBERG, Douglas. Screendance: Inscribing the Ephemeral Image. Oxford University Press, 2012.

RUBIGE, Sarah. 'Defining Digital Dance'. Dance Theatre Journal, vol. 4, no. 14, 1999, pp. 41-45.

RUBIGE, Sarah . 'Identity in Flux: A Practice-Based Interrogation of the Ontology of the Open Dance Work'. Dance and the Performative: A Choreological Perspective: Laban and Beyond, Verve, 2002.

RUBIGE, Sarah. 'Performing Installations - towards an Understanding of Choreography and Performativity in Interactive Installations'. Contemporary Choreography: A Critical Reader, Routledge, 2009.

SHUSTERMAN, Richard. Performing Live: Aesthetic Alternatives for the Ends of Art. Cornell University Press, 2000.

SOUZA, Isabel. 'A Implicação Corpo-Interatividade na Dança Mediada pela Internet'. Anais do $2^{\circ}$ Encontro Nacional de Pesquisadores em Dança, Associação Nacional de Pesquisadores de Dança, 2011, https://proceedings.science/anda/anda-2011/papers/a-implicacao-corpo-interatividade-nadanca-mediada-pela-internet. [accessed 12-09-2020]

VARANDA, Paula. 'Dance Performance in Cyberspace: Self and Social Experienced with the Body'. Proceedings of Post-Screen:Device, Medium and Concept, edited by Ana Vicente and Helena Ferreira, Faculdade de Belas-Artes da Universidade de Lisboa, 2014, pp. 191-99.

VARANDA, Paula.. 'Migrations: Dancing Bodies across Media'. XCoAx 2014 Proceedings of the Second Conference on Computation, Communication, Aesthetics and $X$, edited by Miguel Carvalhais and Mario Verdicchio, Universidade do Porto, 2014, pp. 75-87.

VARANDA, Paula.. 'New Media Dance - Where Is the Performance?' Multimodality and Performance, edited by Carla Fernandes, Cambridge Scholars Publishing, 2016, pp. 187-202.

VARANDA, Paula. 'Soi Moi: The Techno-Soma-Aesthetics of a Dance for the IPhone'. Body, Space \& Technology, vol. 18, no. 1, 1, Open Library of Humanities, Mar. 2019, pp. 267-96. https://doi.org/ 10.16995/bst.314.

WILSON, Stephen. Information Arts: Intersections of Art, Science, and Technology. MIT Press, 2002.

\section{NOTES}

1. The works, the company's biographic details, and press impact are documented in www.muleras.com (accessed 12-09-2021).

2. This interview took place during my research as a $\mathrm{PhD}$ student, and is an appendix to my thesis, archived in Middlesex University Research Repository, available at https:// eprints.mdx.ac.uk/18820/ (accessed 6-10-2021).

3. The stage version of 96 details was called Traces.

4. In Télérama no 2605 - 15 décembre 1999.

5. In Libération, nº 6533 - 17 mai 2002. 
6. In L'Art-Vues, Dec. 2006-Janv. 2007.

7. In the interview (2010), Didier remarked how difficult it was to play dance films on the internet with good quality at the time, due to hardware and broadband limitations that affected speed and pixel resolution.

8. See the website at http://www.mulleras.com/96d/e_accueil96d.html (accessed 12-09-2021)

9. Choreology is the scholar study of dance as a theatrical art

10. I am using this term because each detail can be seen as a single micro-dance performance; the content is made of short durational fragments, the 'theatre' frame is small, and the performer within also appears in a reduced size, sometimes smaller than a thumbnail. Brannigan uses the term micro differently, naming micro-choreographies the works that make an extensive use of the close-up shot.

11. Round, canon effect, achieved by people performing the same move one after the other.

12. The variations enabling choreography by capturing, editing and projecting have been extensively reviewed in relation to dance films (McPherson; and Rosenberg).

13. In a 13 inches screen of a MacBook, that I used for the analysis, the detail frame measured 3,5 inches.

14. Dixon details other categories of interactivity such as participation, conversation and collaboration.

15. McFee discusses the dancers' authorship and their role as artists.

16. A concept of empathy achieved with stimulation of our kinaesthetic sense: the perception of aesthetic qualities in movement, within temporal and spatial coordinates.

17. Fildes shares authorship of his work with Katrina McPherson.

18. I sometimes recorded my screen in order to save my interactive experiments with the work and look at them retrospectively as a source of analysis; I sent one of those movie files to Didier Mulleras, and he published it on Youtube with the title "browsing 96 details", available at https://youtu.be/10rzPEe7MjI, (accessed on 3-11-2020); because it uses flash the artwork is not available on recent computers. Didier Mulleras has the files of the whole work in digital archive and has also published a demo of the interactive modules of 96 details at https://youtu.be/nYoNZETZFHc (accessed on 3-11-2020).

19. In 3D design negative space refers to empty space, the space that has no data in computer terms.

20. The company has always used part of the grants awarded for live performances and that is one of the reasons why their web works are associated with live stage versions.

21. As was the intention of the Web's inventor as Tim Berners Lee. 


\section{ABSTRACTS}

As the World Wide Web became accessible to society on a global scale during the 1990s, artists that stepped into this technological and aesthetic environment experienced transformative effects to their craft and creativity. For dance, a traditionally ephemeral and corporeal action, the limits and values associated with this condition were susceptible to change. 96 details is the result of dance expert knowledge transferred to new media after persistent research on how to approach the web as a theatre and engage world-wide audiences. With this change of format the choreographers challenged the institutional canons of their field and exceeded spectatorship conventions. Such pioneer experience is a remarkable venture into a new format that extends the understanding of what is dance. As the work becomes technologically obsolete, documenting its efficient making and exchanging process that expands concepts of venue, authorship, embodiment and performance, aims to inspire the future of dance and praise the sharing paradigm of the web.

Alors que le World Wide Web est devenu accessible à la société, à l'échelle mondiale, dans les années 1990, les artistes qui sont entrés dans cet environnement technologique et esthétique ont expérimenté des effets transformateurs sur leur métier et leur créativité. Pour la danse, action traditionnellement éphémère et corporelle, les limites et les valeurs associées à cette condition étaient susceptibles de changer. 96 details est le résultat des connaissances des experts en danse transférées aux nouveaux médias après des recherches persistantes sur la façon d'aborder le Web comme un théâtre et d'engager un public mondial. Avec ce changement de format, les chorégraphes ont défié les canons institutionnels de leur domaine et ont dépassé les conventions du spectateur. Une telle expérience de pionnier est une aventure remarquable dans un nouveau format qui élargit la compréhension de ce qu'est la danse. Alors que l'œuvre devient technologiquement obsolète, l'étude des processus de création et d'échange efficace qui élargissent les concepts de lieu, d'auteur, d'incarnation et de performance, vise à inspirer l'avenir de la danse et à louer le paradigme de partage du Web.

\section{INDEX}

Mots-clés: affect, corps, cyberespace, danse, incarnation, art Internet, interactivité, performance, screendance, World Wide Web

Keywords: affect, body, cyberspace, dance, embodiment, Internet art, interactivity, performance, screendance, World Wide Web

\section{AUTHOR}

\section{PAULA VARANDA}

Institute of Art History, School of Social Sciences and Humanities, Universidade NOVA de Lisboa Dr. Paula Varanda was awarded a PhD by Middlesex University in January 2016, with a research about dance and new media. Her work has focused on performing arts and cultural projects in Portugal and Europe, and has been presented in conferences or published in books, newspapers and brochures. She was dance critic for Público newspaper (2004-2016); director of DANSUL - an Arts and Community regional project in Portugal (2008-2015); and director of the General Directorate for the Arts in the Ministry of Culture in Portugal (2016-2018). Since 2019 she has 
been associate researcher at the Institute of Art History at Universidade Nova (IHA/FSCH-UNL) in Lisbon. https://institutodehistoriadaarte.wordpress.com/paula-varanda/ 